\title{
Silvicultura Urbana: Levantamento e caracterização da arborização em uma área central na cidade de Cáceres-MT
}

\author{
Cristman Taísse Félix dos Santos \\ Instituto Federal de Educação, Ciência e Tecnologia de Mato Grosso (IFMT) \\ (cristman.felix@gmail.com) \\ luri Maicon Moreira de Oliveira \\ Instituto Federal de Educação, Ciência e Tecnologia de Mato Grosso (IFMT) \\ (iurii.moreiira@gmail.com) \\ Leonardo Leite Fialho Júnior \\ Instituto Federal de Educação, Ciência e Tecnologia de Mato Grosso (IFMT) \\ (leonardolfialho@gmail.com) \\ Otávio Miranda Verly \\ Instituto Federal de Educação, Ciência e Tecnologia de Mato Grosso (IFMT) \\ (verly.miranda@gmail.com) \\ Poliane Rodrigues Rosa \\ Instituto Federal de Educação, Ciência e Tecnologia de Mato Grosso (IFMT) \\ (polianerodriguesrosa@hotmail.com) \\ Fernanda Miguel Franco \\ Instituto Federal de Educação, Ciência e Tecnologia de Mato Grosso (IFMT) \\ (fernanda.franco@cas.ifmt.edu.br) \\ Arthur Guilherme Schirmbeck Chaves \\ Instituto Federal de Educação, Ciência e Tecnologia de Mato Grosso (IFMT) \\ (arthur.chaves@cas.ifmt.edu.br)
}

Resumo: A arborização urbana desempenha papel fundamental na qualidade de vida da população. Nos últimos anos, houve um aumento significativo da preocupação com a preservação das áreas verdes nos centros urbanos. O presente estudo teve por objetivo a execução do levantamento qualiquantitativo da arborização de uma área do centro histórico da cidade de Cáceres-MT. O trabalho foi realizado em um trecho da Rua 13 de Junho que possui aproximadamente 850 metros de comprimento. Foram levantadas 17 espécies de árvores, arbustos e palmeiras; as quais se distribuíram em 13 famílias botânicas. A espécie Licania tomentosa representou aproximadamente $47 \%$ dos indivíduos; enquanto cerca de 12 espécies foram representadas por apenas um indivíduo, totalizando $24,49 \%$. Em relação ao aspecto fitossanitário, copas com presença de lesão foi a característica de maior ocorrência $(83,78 \%)$. Outros problemas encontrados foram troncos com presença de lesão $(43,24 \%)$, lesão de casca $(40,54 \%)$ e copa com presença de galhos secos $(27,03 \%)$. Quanto ao nível de sombreamento a maioria das espécies apresentaram pouca sombra, ou sombra mediana. Ao analisar o porte, aproximadamente $55,10 \%$ dos indivíduos apresentam porte médio. O presente diagnóstico pode ser utilizado como um indicador de qualidade da arborização, podendo ser incorporado a programas municipais para melhoria dos espaços públicos.

Palavras-chave: Arborização urbana, fitossanidade, inventário florístico.

\section{Urban Forestry: Survey and characterization of afforestation in a central area in the city of Cáceres-MT}

Abstract: The urban afforestation plays a fundamental role in the quality of life of the population. In recent years, concern has been growing over the preservation of green areas in urban centers. The objective of this study was to carry out the qualitative and quantitative survey of the afforestation of an area of the historical center of the city of Cáceres-MT. The work was carried out on a stretch of street June 13 which has approximately 850 meters long. Seventeen species of trees, shrubs and palm trees were found; which they were distributed in 13 botanical families. The species Licania tomentosa represented approximately $47 \%$ of the individuals; while about 12 species were represented by only one individual, totaling $24.49 \%$. Regarding the phytosanitary aspect, the crown of the trees with presence of lesion was the characteristic of greater occurrence $(83.78 \%)$. Other problems were trunks with presence of lesion (43.24\%), bark injury (40.54\%) and treetops with dry branches $(27.03 \%)$. As 
for the level of shading most of the species showed little shade, or medium shade. When analyzing the size, approximately $55.10 \%$ of the individuals presented medium size. The diagnosis can be used as an indicator of the quality of afforestation and can be incorporated into municipal programs to improve public spaces.

Keywords: Urban tree planting, plant health, floristic survey.

\section{INTRODUÇÃO}

Desde a década de 70 as cidades brasileiras têm sofrido as mais intensas alterações. A compreensão da diversidade dos aspectos do espaço urbano, relacionados às suas dimensões socioambientais, tornou-se uma preocupação cada vez mais presente para o planejamento e a gestão urbana. Os temas relacionados à qualidade ambiental das áreas urbanas vêm sendo debatidos por diversos pesquisadores em vários níveis. Dentre os temas de relevância, a vegetação intraurbana ganhou destaque nos últimos anos devido às funções que esta pode exercer na melhoria das condições do ambiente urbano (BARGOS e MATIAS, 2011).

Nesse sentido a implantação da arborização nas cidades é de suma importância para a melhoria da qualidade de vida, além de contribuir com os aspectos ambientais, estéticos e paisagísticos. Barcellos et al. (2012) define a arborização urbana como toda cobertura vegetal existente nos espaços urbanos, sendo eles, ruas, praças, parques, jardins e canteiro central.

Segundo Pivetta e Silva Filho (2002), a arborização contribui para a manutenção da estabilidade microclimática, conforto térmico, melhoria da qualidade do ar, redução da poluição, proteção e direcionamento do vento, entre outros. Entretanto, muitos municípios brasileiros ainda não possuem nenhum tipo de planejamento que trate sobre a arborização urbana, ou quando têm, não o executam devidamente.

O plano municipal de arborização urbana a ser elaborado pela prefeitura deve levar em conta as seguintes questões: o quê, como, onde e quando plantar. Além de considerar fatores básicos como as condições climáticas locais, espaço físico disponível e características das espécies a serem utilizadas. O projeto deve obedecer a determinadas normas e respeitar os valores culturais, ambientais e memória da cidade. 
O município de Cáceres localizado na região sudoeste de Mato Grosso, fundado no dia 06 de outubro de 1778 no final do século XVIII (PINHO, 2013), apresenta características de ocupação desorganizada. Segundo o mesmo autor, à medida em que a cidade era povoada, novas ruas e avenidas foram abertas a fim de atender o setor econômico. Apesar do município contar com o plano diretor de desenvolvimento (PDD), ainda faltam políticas que subsidiem o planejamento da arborização nas vias públicas.

Os objetivos da realização de um inventário arbóreo foram resumidos por Motta (2000) da seguinte forma: conhecimento do patrimônio arbóreo, definição de uma política pública de longo prazo, realização correta de antevisões orçamentárias futuras, monitoramento de um programa de manejo das árvores, definição das prioridades nas intervenções, localização das áreas mais adequadas para plantio, de maciços novos ou de manutenção, e localizar árvores que necessitem de remanejamento através de supressão ou transplante.

Assim, este trabalho teve por objetivo fazer um levantamento qualiquantitativo da arborização urbana em um trecho da Rua 13 Junho no Centro Histórico de Cáceres-MT.

\section{METODOLOGIA}

\subsection{Caracterização da área de estudo}

O município de Cáceres se encontra no sudoeste do estado de Mato Grosso, entre as latitudes $15^{\circ} 27^{\prime}$ e $17^{\circ} 37^{\prime}$ sul e longitudes $57^{\circ} 00^{\prime}$ e $58^{\circ} 48^{\prime}$ oeste, e altitude média de $118 \mathrm{~m}$ (SOUZA et al., 2015). Segundo dados do IBGE (2010) no censo de 2010, o município possuía 87.942 habitantes.

A cidade é conhecida como "O portal do Pantanal", pois se situa no início da região pantaneira, sendo banhada pelo Rio Paraguai. A região se encontra em zona de transição de biomas, apresentando, portanto, componentes florísticos do Pantanal, Cerrado e Amazônia. De acordo com a classificação climática de Köppen, o clima é do tipo AWa (tropical de savana) quente e úmido, com inverno seco (NEVES et al., 2011). 
Foi realizado um levantamento quali-quantitativo das espécies arbóreas situadas em um trecho da Rua 13 de Junho com aproximadamente 850 metros, iniciando-se na esquina da Avenida São João até o cruzamento com a Rua Prof. Rizo, no centro da cidade de Cáceres-MT, ás margens do Rio Paraguai. O percurso transcorre a Praça Barão do Rio Branco e a Catedral de São Luiz de Cáceres, importantes pontos turísticos da cidade. Todavia, ressalta-se que não foram avaliados os indivíduos que se encontravam na área da praça, apenas aqueles às margens da rua e nos canteiros centrais, Figura 1.

\subsection{Levantamento quali-quantitativo da arborização}

O levantamento da arborização constou da identificação botânica e do levantamento de informações referentes às espécies, baseados na literatura especializada, (SANCHOTENE, 1985; LORENZI, 1992).

Os indivíduos arbóreos foram identificados por meio de nomes vulgar e científico, além de realizar análise da qualidade fitossanitária e porte dos mesmos quando adultos. Foram observados ainda, o nível de sombreamento da copa, a existência, ou não, de poda, conflitos da arborização com a rede elétrica, passagem de pedestres e com a sinalização de trânsito.

A identificação foi realizada preliminarmente in loco por meio do nome vulgar da árvore, sendo realizada posteriormente a identificação botânica das espécies. As demais observações foram realizadas por meio de análise visual.

As situações fitossanitárias foram avaliadas com base nos problemas de pragas, doenças ou danos físicos encontrados. Dessa forma realizou-se uma análise visual do aspecto físico dos indivíduos arbóreos encontrados. Foi considerada uma classificação com um total de 13 situações problemas elencados em ordem alfabética de $\mathrm{A}$ até $\mathrm{M}$, que acometem árvores em áreas urbanas. As situações são as seguintes: A- Base com presença de brotações, B- Base com presença de cavidades, C- Base com presença do fungo orelha-de-pau, D- Base com infestação de insetos, E- Tronco com presença de cavidade, F- Tronco com presença do fungo orelha-de-pau, G- Tronco com infestação de insetos, H- Tronco com presença de lesão, I- Lesão de casca, J- Copa com presença de erva-de-passarinho, K- Copa com presença de folhas de coloração anormal, L- Copa com presença de galhos secos e M- Copa com presença de lesão. 
As informações sobre a arborização foram coletadas de todos os indivíduos encontrados no trecho estudado. Em seguida os dados foram processados em planilha eletrônica Microsoft Office Excel 2017, gerando-se gráficos e tabelas para análise e discussão dos resultados.

Figura 1: Localização da área de estudo na Rua 13 de Junho.

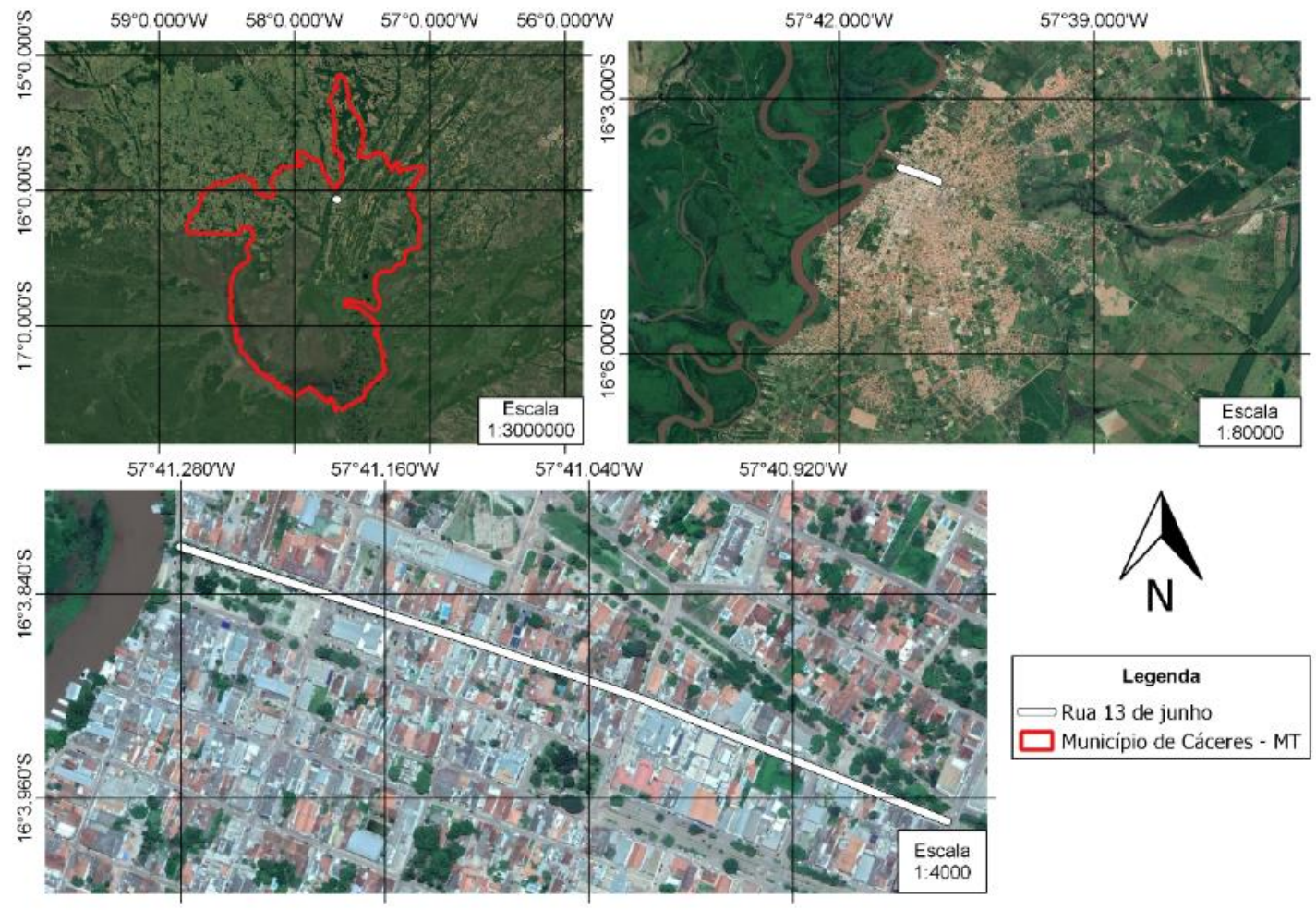

Fonte: Autores, 2018.

\section{RESULTADOS E DISCUSSÃO}

\subsection{Levantamento Arbóreo}

Foram levantados 49 indivíduos arbóreos, sendo encontradas 17 espécies, entre árvores, arbustos e palmeiras, as quais se distribuíram em 13 famílias botânicas. Apenas Arecaceae Schultz Sch., Bignoniaceae Juss., Fabaceae Lindl. e Moraceae Gaudich apresentaram duas espécies, sendo que as demais foram monoespecíficas, conforme tabela 1. 
A diversidade de espécies encontrada na arborização é alta, no entanto a proporção entre o número de espécies e o número de indivíduos encontrados é pequena. Sendo assim, não há proporcionalidade do número de indivíduos em relação as espécies, de modo que algumas espécies são representadas por apenas um indivíduo, enquanto outras possuem a maioria das plantas.

Licania tomentosa (Benth.) Fritsch foi a espécie com maior representatividade, com 46,94\% dos indivíduos. Patrício (2017) em estudo desenvolvido na UFMT (Universidade Federal de Mato Grosso) em Cuiabá, também encontrou L. tomentosa com a espécie mais abundante na arborização do campus, sendo muito utilizada em ruas, estacionamentos e em locais de intensa passagem de pedestres. Em estudos de Moura e Santos (2009), na arborização urbana de Várzea Grande - MT, a espécie L. tomentosa também apresentou significativa representatividade, com $33,81 \%$ dos indivíduos.

Em menor quantidade, outras espécies encontradas foram Handroanthus impetiginosus (Mart. ex DC.) e Ficus benjamina com 5 indivíduos (10,20\%) cada, Pachira aquatica Aubl e Moringa oleifera Lam. com 2 indivíduos (4,08\%) cada, totalizado $28,56 \%$ dos indivíduos. O restante das espécies, no total de 12 , foram representadas por apenas um indivíduo, somando $24,49 \%$.

É importante ressaltar o valor ornamental apresentado pela espécie Handroanthus impetiginosus que é muito utilizada pela população para a arborização de diferentes locais. Outra árvore muito conhecida é o ipê roxo (Handroanthus heptaphyllus (Vell.) Mattos), uma espécie nativa pertencente à família Bignoniaceae, apresenta porte arbóreo e elevado valor comercial. Frequentemente é utilizada para programas de reflorestamento e recuperação de áreas degradadas, bem como na medicina popular (CARVALHO, 2003).

Também há duas espécies frutíferas, Mangifera indica L. e Eugenia uniflora L., atraindo assim pássaros e pessoas ao local. Em trabalho realizado por Pereira et al. (2005) na cidade de Recife, verificou-se que as árvores são as que mais contribuem para alimentar as aves através de seus frutos. No tocante à avifauna, observou-se que 13 espécies se alimentam de frutos oferecidos pela arborização pública recifense. No caso da utilização de espécies frutíferas em calçadas, deve-se optar por aquelas que apresentem frutos pequenos, leves e não carnosos (BIONDI e ALTHAUS, 2005). 
Levando em consideração a área do levantamento, uma via de 850 metros, a variação das espécies e o espaçamento entre elas aconteceu de forma aleatória visto que o poder público não tem uma política de arborização urbana.

Tabela 1. Espécies arbóreo-arbustivas e palmáceas presentes na arborização urbana da Rua 13 de Junho no Centro Histórico de Cáceres.

\begin{tabular}{|c|c|c|c|c|}
\hline Espécie & Nome Popular & $\begin{array}{c}\mathrm{N}^{\circ} \text { de } \\
\text { Indivíduos }\end{array}$ & $\begin{array}{c}\text { Frequência } \\
(\%)\end{array}$ & Origem \\
\hline \multicolumn{5}{|l|}{ Anacardiaceae R.Br. } \\
\hline $\begin{array}{l}\text { Mangifera indica L. } \\
\text { Apocynaceae Juss. }\end{array}$ & Mangueira & 1 & 2,04 & Ext \\
\hline $\begin{array}{l}\text { Thevetia thevetioides (Kunth) K. } \\
\text { Schum } \\
\text { Arecaceae Schultz Sch. }\end{array}$ & Chapéu-de-Napoleão & 1 & 2,04 & Ext \\
\hline $\begin{array}{l}\text { Copernicia alba Morong ex } \\
\text { Morong \& Britton }\end{array}$ & Carandá & 1 & 2,04 & Nat \\
\hline $\begin{array}{l}\text { Roystonea oleracea (Jacq.) O. F. } \\
\text { Cook }\end{array}$ & Palmeira-Imperial & 1 & 2,04 & Ext \\
\hline \multicolumn{5}{|l|}{ Bignoniaceae Juss. } \\
\hline $\begin{array}{l}\text { Handroanthus impetiginosus } \\
\text { (Mart. ex DC.) Mattos }\end{array}$ & Ipê-Rosa & 5 & 10,20 & Nat \\
\hline $\begin{array}{l}\text { Handroanthus heptaphyllus } \\
\text { (Vell.) Mattos }\end{array}$ & Ipê-Roxo & 1 & 2,04 & Nat \\
\hline $\begin{array}{l}\text { Chrysobalanaceae R.Br. } \\
\text { Licania tomentosa (Benth.) } \\
\text { Fritsch }\end{array}$ & Oiti & 23 & 46,94 & MAtla \\
\hline \multicolumn{5}{|l|}{ Combretaceae R.Br. } \\
\hline \multicolumn{5}{|l|}{ Fabaceae Lindl. } \\
\hline Dipteryx alata Vogel & Cumbaru & 1 & 2,04 & Nat \\
\hline $\begin{array}{l}\text { Parkia platycephala Benlh. } \\
\text { Malvaceae Juss. }\end{array}$ & Fava-de-Bolota & 1 & 2,04 & Nat \\
\hline $\begin{array}{l}\text { Pachira aquatica Aubl. } \\
\text { Meliaceae Juss. }\end{array}$ & Falso-Cacau & 2 & 4,08 & Ext \\
\hline $\begin{array}{l}\text { Azadirachta indica A. Juss. } \\
\text { Moraceae Gaudich }\end{array}$ & Neem & 1 & 2,04 & Ext \\
\hline Ficus benjamina L. & Figueira-Benjamin & 5 & 10,20 & Ext \\
\hline $\begin{array}{l}\text { Ficus cf. gomelleira Kunth } \\
\text { Moringaceae Martinov }\end{array}$ & Figueira & 1 & 2,04 & Nat \\
\hline $\begin{array}{l}\text { Moringa oleifera Lam. } \\
\text { Myrtaceae Juss. }\end{array}$ & Moringa & 2 & 4,08 & Ext \\
\hline $\begin{array}{l}\text { Eugenia uniflora L. } \\
\text { Rutaceae A.Juss. }\end{array}$ & Pitanga & 1 & 2,04 & MAtla \\
\hline Murraya paniculata (L.) Jack & Murta-de-Cheiro & 1 & 2,04 & Ext \\
\hline
\end{tabular}

Nota: Ext - Exótica; MAtla - Mata Atlântica; Nat - Nativa.

Fonte: Autores, 2018

Em relação a origem das espécies 35,29\%, que representam seis indivíduos, são nativas dos biomas Cerrado e Pantanal, ou seja, são autóctones. Em 
compensação, nove espécies são de origem exótica, sendo Moringa, Neem, Sete Copas, Falso Cacau, Figueira Benjamin e Mangueira da Ásia, a Palmeira Imperial e Chapéu de Napoleão da América Central e a Murta-de-Cheiro da Europa.

No levantamento também foi verificado duas espécies oriundas da Mata Atlântica, sendo que a estes dois grupos de espécies atribui-se o termo alóctone, já que estas espécies não possuem ocorrência natural nos biomas adjacentes à área de estudo, Figura 2-A.

A baixa representatividade das espécies nativas também é evidente quando se observa o número de indivíduos, dos quais 79,59\% correspondem a plantas alóctones, sendo que deste total $61,54 \%$ das árvores são de espécies nativas da Mata Atlântica, Figura 2-B.

Figura 2: A - Distribuição das espécies levantadas conforme sua origem; B - Distribuição dos indivíduos conforme a origem das espécies.

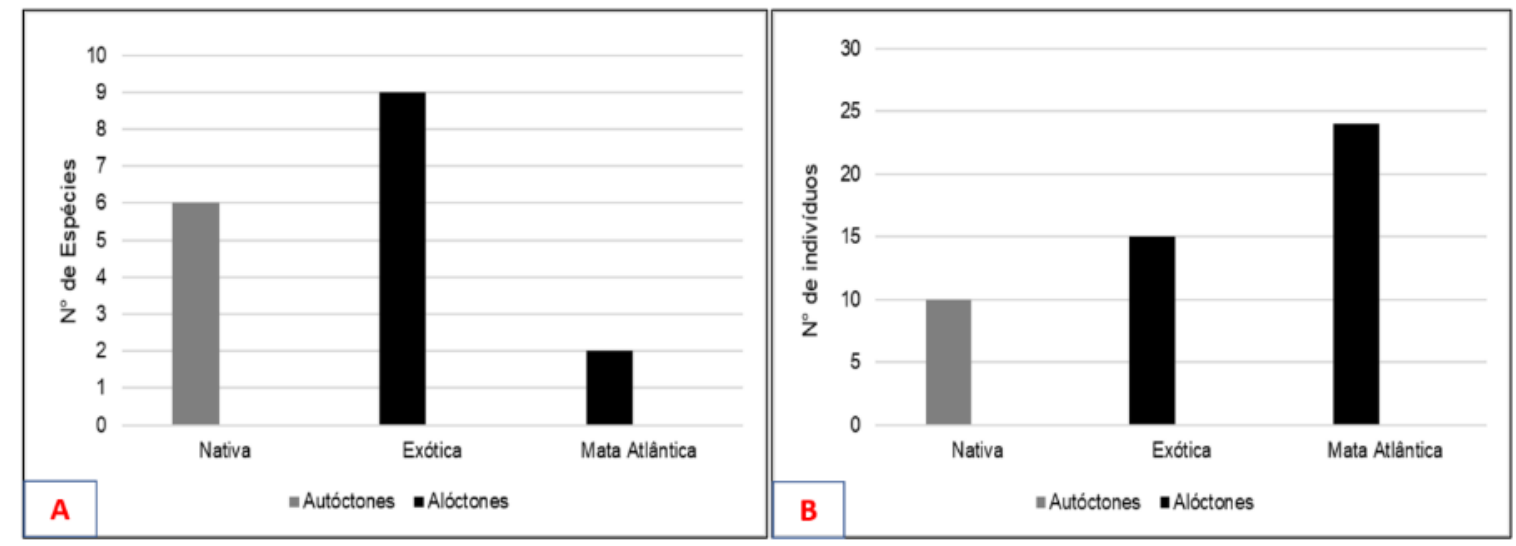

Fonte: Autores, 2018

Nota-se ainda, que as espécies exóticas também não apresentaram grande representatividade avaliando-se o número de indivíduos. As espécies exóticas levantadas também foram encontradas em outros estudos da composição florística da arborização urbana, como: Mangifera indica L. e Roystonea oleracea (Jacq.) O. F. Cook (MARANHO et al., 2012; RICHTER et al., 2012; NUNES et al., 2013; TEIXEIRA, 2015; PERIOTTO et al., 2016), Thevetia thevetioides (Kunth) K. Schum (NUNES et al., 2013), Terminalia catappa L. (MOURA e SANTOS, 2009; MARANHO et al., 2012; SANTOS et al., 2012; NUNES et al., 2013; PERIOTTO et al., 2016), Pachira aquatica Aubl. (MOURA e SANTOS, 2009; NUNES et al., 2013), Ficus benjamina L. (MOURA e SANTOS, 2009; MARANHO et al., 2012; NUNES et al., 
2013; TEIXEIRA, 2015; PERIOTTO et al., 2016), e Murraya paniculata (L.) Jack (NUNES et al., 2013; LOCASTRO e DE ANGELIS, 2015; PERIOTTO et al., 2016).

Segundo Matos e Queiroz (2009) foi na época do Brasil colônia que as espécies exóticas começaram a ser introduzidas no país, trazidas da Europa para aproximar a paisagem brasileira com as terras europeias. Entretanto a difusão de espécies exóticas nos dias de hoje está relacionada principalmente com o interesse por plantas ornamentais. Para Blum et al. (2008), as espécies exóticas, se implantadas de forma planejada, não oferecem risco a biodiversidade do local, entretanto, quando introduzidas de maneira desordenada e sem planejamento, algumas espécies acabam tornando-se invasoras, por terem a capacidade de dominar o ambiente e causarem risco a biodiversidade.

\subsection{Situações Fitossanitárias}

Em um total de 49 dos indivíduos levantados, 37 (83,78\%) apresentaram problema fitossanitário, enquadrando-se na classe M (copa com presença de lesão). Resultados como o encontrado neste estudo também foram verificados por Macêdo et al. (2012) em Natal-RN, que constataram altos percentuais em relação a danos físicos em Anacardium occidentale (57,38\%), Terminalia catappa (33,61\%) e Senna siamea (25,95\%), em sua maioria, relacionados ao uso de técnicas inadequadas de poda e à idade das árvores.

A classe M - Copa com presença de lesão apresentou o maior percentual dos indivíduos com problemas fitossanitários. A seguir os outros problemas encontrados foram representados pelas classes H - Tronco com presença de lesão com 43,24\% dos indivíduos afetados, I - Lesão de casca com 40,54\% e L - Copa com presença de galhos secos com $27,03 \%$, conforme representado no gráfico da Figura 3. 
Figura 3: Quantificação da situação fitossanitária das espécies encontradas.

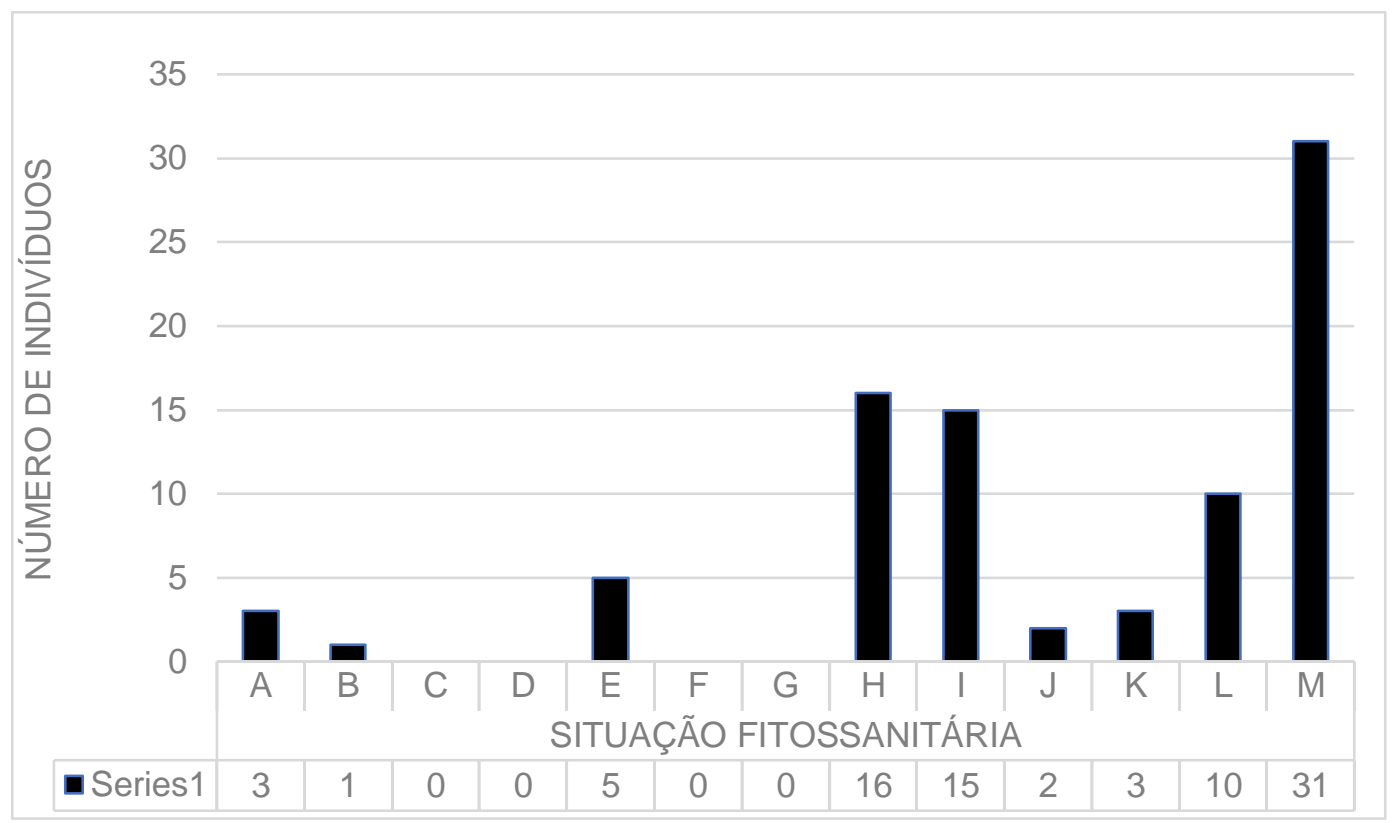

Fonte: Autores, 2018

Nota: A- Base com presença de brotações, B- Base com presença de cavidades, C- Base com presença do fungo orelha-de-pau, D- Base com infestação de insetos, E- Tronco com presença de cavidade, F- Tronco com presença do fungo orelha-de-pau, G- Tronco com infestação de insetos, HTronco com presença de lesão, I- Lesão de casca, J- Copa com presença de erva-de-passarinho, KCopa com presença de folhas de coloração anormal, L- Copa com presença de galhos secos e MCopa com presença de lesão.

A alta percentagem da classe $M$ pode estar relacionada com os serviços de poda realizados nas copas das árvores, a fim de evitar conflito com a rede elétrica. Essa grande incidência de indivíduos que sofreram algum tipo de poda pode refletir ainda, se a escolha das espécies foi adequada para o local. Nota-se, inclusive, que a maior frequência desta classe ocorre nos indivíduos de Licania tomentosa (Benth.) Fritsch, que possui como característica o desenvolvimento de copa frondosa, necessitando de podas mais frequentes.

Para a arborização urbana a poda é importante porque confere à árvore uma arquitetura adequada durante o seu desenvolvimento, por eliminar ramos mortos, danificados, doentes, praguejados e que comprometam, com o crescimento, a segurança elétrica da rede e a estrutura das residências. Assim, a poda empregada de forma correta, evita que a queda de ramos mortos coloque em risco a integridade física das pessoas e do patrimônio público e particular, bem como, impedir o emprego de agrotóxicos no meio urbano e evitar que a permanência de ramos danificados comprometa o desenvolvimento sadio das árvores (NOGUEIRA et al., 2016). 
Gomes et al. (2016) ressaltam que a prática de podar pode torna-se perigosa quando realizada por pessoas não especializadas, podendo se tornar a porta de entrada para possíveis doenças e pragas.

Quanto às situações-problemas relativas ao tronco das espécies levantadas, as classes $\mathrm{H}$ e I estão relacionadas às lesões causadas por veículos que esbarram no tronco das árvores, atos de vandalismo e às doenças que acometem a casca da árvore, deixando o tronco lesionado e com susceptibilidade de infecção. A ocorrência significativa da classe L (Copa com presença de galhos secos), demonstra que devem ser realizadas podas para a retirada dos galhos secos, evitando maiores problemas.

Freitas et al. (2015), avaliando a fitossanidade em quatro praças no Rio de Janeiro, verificou que $64,50 \%$ dos indivíduos arbóreos estavam saudáveis, demonstrando boas condições de raízes e parte aérea; 25,40\% apresentaram sintomas comuns de ataques de pragas e organismos patogênicos, como manchas nas folhas, perfurações no tronco e raízes, queda prematura das folhas e parte aérea visivelmente danificada; $10,10 \%$ sofreram injúrias mecânicas de vários tipos, como cortes nos troncos, por objetos aderidos de forma inadequada, como pregos, correntes, ataque bem avançado de organismos patogênicos no tronco, criando ocos e podridões do caule. O mesmo padrão foi observado por Redin et al. (2010) ao analisarem o estado fitossanitário das árvores presentes em cinco praças situadas no município de Cachoeira do Sul, RS.

A partir destes resultados podemos destacar que ações de manejo relacionadas à poda das árvores devem ser reavaliadas, de forma que esta prática seja feita adequadamente, por profissionais especializados e autorizados pela prefeitura.

\subsection{Sombreamento e Porte dos Indivíduos}

O levantamento apontou que dos 49 indivíduos amostrados, 45 foram podados recentemente, e quatro necessitam de poda de limpeza. Sendo essas árvores, duas da espécie Moringa oleifera Lam., localizadas em frente ao Ambulatório da Criança, e duas da espécie Licania tomentosa (Benth.) Fritsch., próximas a Praça Barão do Rio Branco, visto que apresentam situação conflitante com o cabeamento aéreo de energia, conforme ilustrado pela Figura 4. 
Os locais onde se encontram as espécies são regiões de intenso tráfego de pedestre, logo, a não efetuação de podas apresenta risco potencial para os transeuntes, uma vez que estão expostos a acidentes de qualquer natureza, podendo, ainda, provocar curtos-circuitos, incêndios, entre outros.

Identificou-se cinco indivíduos jovens de Handroanthus impetiginosus (Mart. ex DC.) Mattos, que futuramente podem apresentar conflito com a rede de energia, uma vez que esta espécie quando adulta apresenta grande porte. Neste caso, ressalta-se a importância de conhecer os aspectos biológicos da planta que será destinada a arborização urbana. É de conhecimento geral que ipês têm uma beleza cênica icônica quando florescem, sendo alvo de fotografias e contemplação. Todavia, deve-se ter cautela na escolha do local de plantio, de modo que calçadas e passeios públicos estreitos ou com cabos de alta e baixa tensão aéreos não são recomendados.

Figura 4: A-B - Árvores de L. tomentosa em conflito com cabeamento elétrico próximo à Praça Barão do Rio Branco.

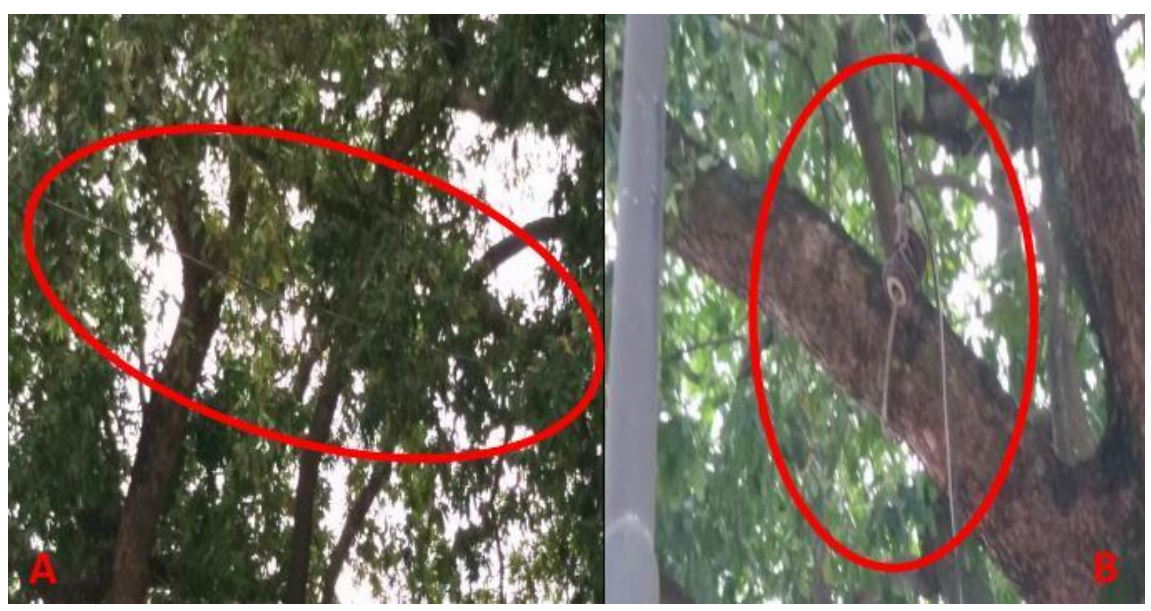

Fonte: Autores, 2017.

Em relação às árvores que causam problemas para os pedestres, oito indivíduos apresentaram situação conflitante, como, por exemplo, a espécie $L$. tomentosa, onde uma das árvores encontra-se ocupando parte de uma passarela para pedestres na Praça Barão do Rio Branco, Figura 5. Outros três indivíduos L. tomentosa posicionados em calçadas residenciais em frente à Praça do Córrego Sangradouro, Figura 6. O restante das espécies são Parkia platycephala Benlh, 
Moringa oleifera Lam., Ficus benjamina L. e Murraya paniculata (L.) Jack, com apenas uma situação conflitante cada.

Recomenda-se, segundo a COMPANHIA ENERGÉTICA DE SÃO PAULO CESP (1988), que a copa das árvores seja bem formada, com altura de até sete metros na fase adulta, de maneira que não interfira na fiação elétrica e telefônica, nem na passagem de pedestres.

Figura 5:Indivíduo de Licania tomentosa (Benth.) Fritschocupando parte de passarela para pedestres próximo à Praça Barão do Rio Branco.

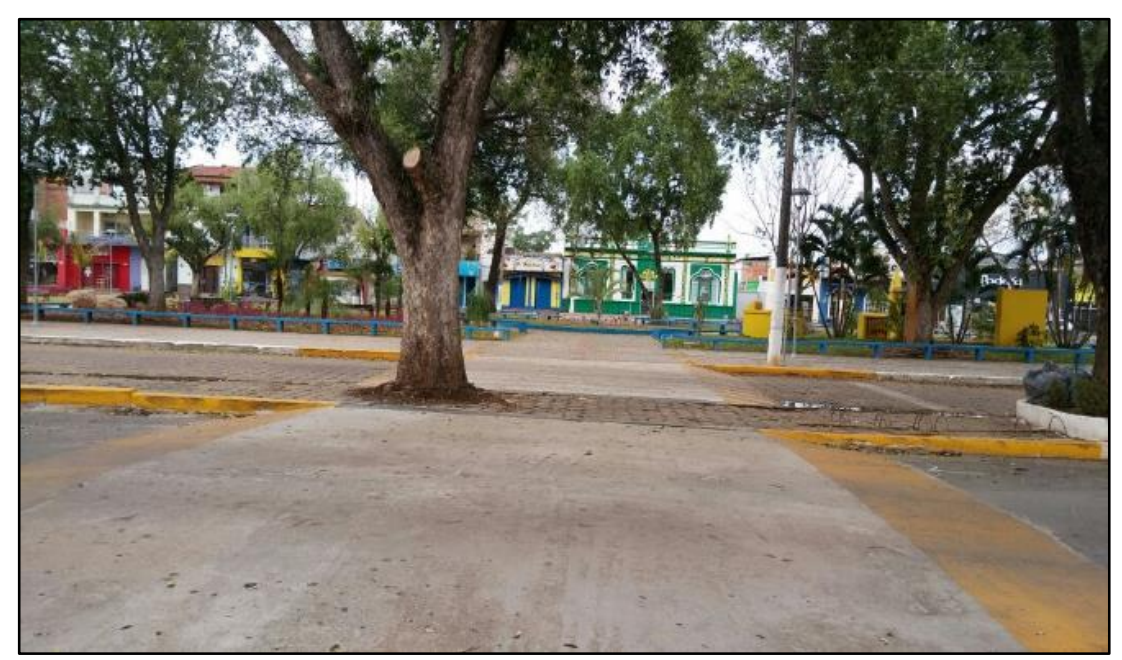

Fonte: Autores, 2017.

Figura 6:Troncos de indivíduos mortos de Licania tomentosa (Benth.) Fritsch em conflito com a passagem de pedestres em calçada residencial.

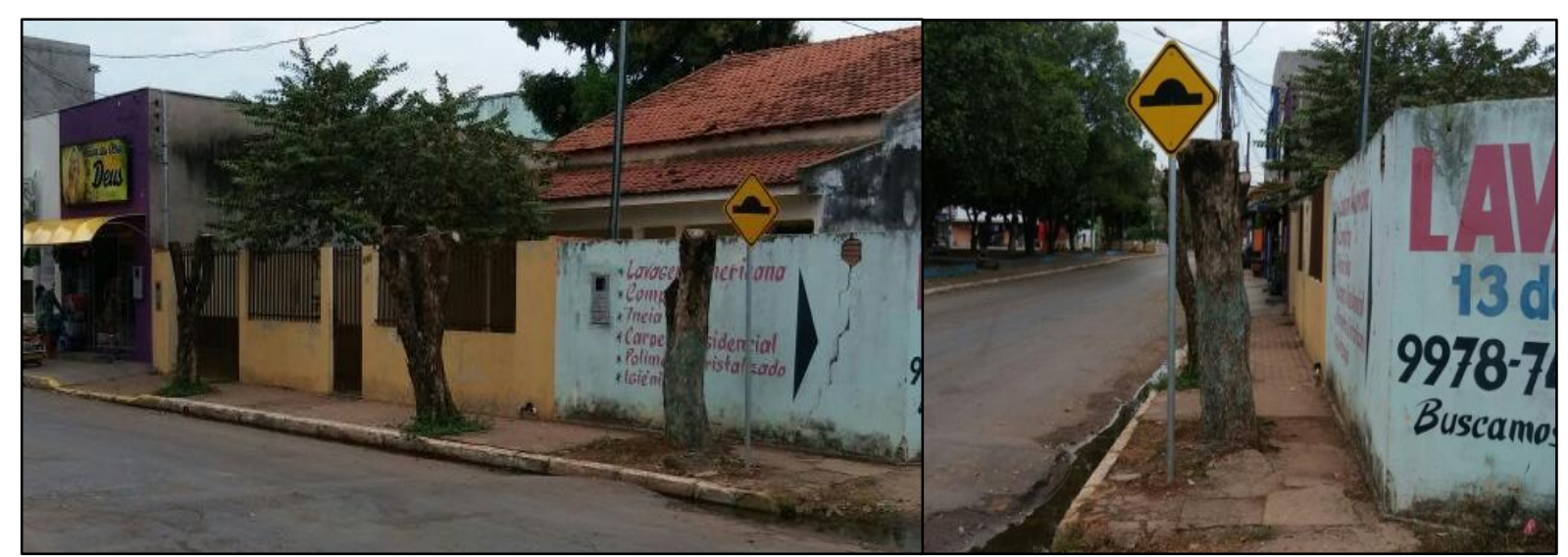

Fonte: Autores, 2017.

Quanto ao sombreamento dos indivíduos, 12 árvores não apresentaram nenhuma sombra, 14 árvores pouca sombra, 16 árvores sombra mediana e 7 
árvores muita sombra. Deve-se levar em conta que a época do ano do levantamento (agosto/2017) é um período mais seco na região de Cáceres-MT (inverno) e que comumente algumas espécies tendem a ficar sem folhagem, o que pode ter influenciado os dados de sombreamento.

Existe uma grande variedade de densidade e formato de copas, que proporcionam diferentes níveis de sombreamento, que devem ser observados atentamente pelos planejadores, a fim de que sejam compatíveis com as condições climáticas dos locais aonde serão inseridas (MALAMUT, 2011). Da mesma maneira, é necessário levar em consideração as mudanças de forma e tamanho que ocorrerão com o passar dos anos, observando o dimensionamento do ambiente e condições de insolação às quais as árvores estarão sujeitas (MASCARÓ; MASCARÓ, 2010).

FISCHER (1985) considera espécies de copa arredondada e ovalada ideais para arborização, pois evitam, problemas com as redes elétrica. $\mathrm{Na}$ copa arredondada existem ramos ortotrópicos que crescem eretos (HALLÉ et al., 1978) e com ramificação simpodial (STRASBURGER, 1988), enquanto que na copa ovalada prevalecem os ramos plagiotrópicos, que são quase horizontais com simetria dorsiventral (HALLÉ et al. 1978) e dificilmente se adaptarão em espaços pequenos (SEITZ, 1990). O modelo arquitetônico de cada espécie deve ser considerado para garantir a sua vitalidade quando houver podas (SEITZ, 1990).

Quanto ao porte, 3 indivíduos apresentaram porte pequeno, 26 médio porte e 9 grande porte. A maioria dos indivíduos de porte médio é pertencente a espécie Licania tomentosa (Benth.) Fritsch. Levantou-se 11 indivíduos jovens, classificados em porte pequeno. Destes, 10 apresentam porte grande na fase adulta e uma de porte mediano. Dos que apresentam porte grande, destacam-se Handroanthus impetiginosus (Mart. ex DC.) Mattos, com cinco indivíduos, e Ficus benjamina L. com três árvores. Os outros indivíduos são das espécies Pachira aquatica Aubl. e Dipteryx alata Vogel, com uma árvore cada.

\section{CONCLUSÕES}

A diversidade total de espécies encontrada foi alta, todavia não há equilíbrio entre o número de indivíduos, uma vez que apenas Licania tomentosa (Benth.) Fritsch foi responsável por aproximadamente $47 \%$ dos indivíduos. Desta forma é 
necessária a criação de um plano municipal de arborização, a fim de adquirir uma melhor razão entre número de espécies e número de indivíduos. Quanto à origem das espécies, apenas 35,29\% dos indivíduos são nativos dos biomas da região, logo é necessário melhorar esta percentagem, uma vez que espécies autóctones apresentam melhor adaptação ao plantio, além de valorizar a flora regional, com a qual a população possui melhor relacionamento.

Em relação ao aspecto fitossanitário, copa com presença de lesão foi o maior caso de ocorrência com 83,78\%, outros problemas encontrados foram tronco com presença de lesão com 43,24\% dos indivíduos afetados, lesão de casca com $40,54 \%$ e copa com presença de galhos secos com $27,03 \%$.

A lesão de copa é causada principalmente por podas agressivas, sendo assim é importante o plano de manejo que deve ser realizado pelo poder público garantido assim o crescimento saudável das árvores urbanas. A lesão de casca e tronco foi provocada por vandalismo e veículos, sendo assim é importante a educação ambiental assim como a proteção das espécies.

Quanto ao sombreamento a maioria das espécies apresentaram pouca sombra, ou sombra mediana, no entanto deve-se levar em consideração a data do levantamento de dados, visto que, este ocorreu no período seco (agosto 2017). Sendo assim a escolha das espécies arbóreas deve atender a demanda por sombreamento, característica que está relacionada a arquitetura da copa e ao comportamento caducifólio, de forma a contribuir para o conforto térmico e bemestar da população.

Ao analisar o porte das árvores, constatou-se que a maior quantidade de indivíduos era de médio porte com 55,10\%, seguido por grande com $38,78 \%$, e pequeno com $6,12 \%$. A escolha da espécie deve sempre ser adequada ao local onde será plantada, pois arvores de grande porte necessitam de espaço para o seu completo desenvolvimento, se disposta em local inadequado poderá causar conflitos com a rede de energia e a danificação da calçada.

O diagnóstico e análise da arborização urbana é de fundamental importância, pois é um indicador para o poder público. Sendo assim um instrumento para muitas cidades se adequarem e incorporarem em sua gestão ambiental, projetos ou programas de arborização para obtenção de um ambiente urbano mais sustentável. 


\section{REFERÊNCIAS}

BARCELLOS, A.; WOJCIKIEWICZ, C. R.; LUBASZEWSKI, E. A.; MAZUCHOWSKI, J. Z.; CONCEIÇÃO, J. R.; LEAL, L.; MEDEIROS, M. L. M.; CONTE, P. A.; KARVAT, S. G.; AHRENS, S. Manual para elaboração do plano municipal de arborização urbana. Paraná, 2012.

BARGOS, D. C.; MATIAS, L. F. Áreas verdes urbanas: um estudo de revisão e proposta conceitual. REVSBAU, Piracicaba - SP, v.6, n.3, p.172-188, 2011.

BIONDI, D.; ALTHAUS, M. Árvores de rua de Curitiba: cultivo e manejo. Curitiba: FUPEF, 177 p, 2005.

BLUM, C. T.; BORGO, M.; SAMPAIO, A. C. F. Espécies exóticas invasoras na arborização de vias públicas de Maringá - PR. Revista da Sociedade Brasileira de Arborização Urbana, Piracicaba, v.3, n.2, p.78-97, 2008.

CARVALHO, P. E. R. Espécies arbóreas brasileiras: recomendações silviculturais de espécies florestais. Brasília: EMBRAPA Informação Tecnológica, 2003.

COMPANHIA ENERGÉTICA DE SÃO PAULO. Guia de arborização. 3 ed. São Paulo: CESP, 1988. 33p. (Coleção Ecossistemas Terrestres, 006).

FISCHER, G. R. Características positivas de espécies indicadas para arborização pública. In: ENCONTRO NACIONAL SOBRE ARBORIZAÇÃO URBANA, 1, Porto Alegre, 1985. Anais... Porto Alegre, Prefeitura Municipal de Porto Alegre/ Secretaria Municipal do Meio ambiente, p.129-149, 1985.

FREITAS, W. K.; PINHEIRO, M. A. S.; ABRAHÃO, L. L. F. Análise da Arborização de Quatro Praças no Bairro da Tijuca, RJ, Brasil. Floram - Floresta e Ambiente, v. 22, $n^{\circ} 1$, p. 23-31, 2015.

GOMES, E. M. C.; RODRIGUES, D. M. S.; SANTOS, J. T.; BARBOSA, E. J. Análise quali-quantitativa da arborização de uma praça urbana do Norte do Brasil. Revista Nativa, Sinop, v.4, n.3, p.179-186, 2016.

HALLÉ, F.; OLDMAN, R. A. A.; TONLINSOM, P. B. Tropical trees and forest: an architectural analysis. Berlin: Springer Verlag, 1978.

IBGE, Brasil. Mato Grosso: Cáceres: infográficos: evolução populacional e pirâmide etária, 2010.

LOCASTRO, J. K.; DE ANGELIS, B. L. D. Diagnóstico quali-quantitativo da arborização urbana em duas avenidas do município de Maringá - PR. Revista Eletrônica em Gestão, Educação e Tecnologia Ambiental. Santa Maria-RS, v.19, n.3, p. 248-255, 2015.

LORENZI, H. Árvores brasileiras: manual de identificação e cultivo de plantas arbóreas nativas do Brasil. Nova Odessa: Ed. Plantarium, 352p,1992. 
MACÊDO, B. R. M.; LISBOA, C. M. C. A.; CARVALHO, F. G. de. Diagnóstico e diretrizes para a arborização do campus central da Universidade Federal do Rio Grande do Norte. Revista da Sociedade Brasileira de Arborização Urbana, Piracicaba - SP, v.7, n.1, p.35-51, 2012.

MALAMUT, Marcos. Paisagismo: Projetando espaços livres. Lauro de Freitas: Livro.com, n. 1, p.148, 2011.

MARANHO, A. S.; PAULA, S. L. Q. P.; LIMA, E.; PAIVA, A. V.; ALVES, A. P.; NASCIMENTO, D. O Levantamento Censitário da Arborização Urbana Viária de Senador Guiomard, Acre. Revista da Sociedade Brasileira de Arborização Urbana, Piracicaba - SP, v.7, n.3, p. 44-56, 2012.

MASCARÓ, L.; MASCARÓ, J. L. Vegetação Urbana. Porto Alegre: Mas quatro, n. 3, p. 212, 2010.

MATOS, E.; QUEIROZ, L.P. de. Árvores para cidades. Salvador: Ministério Publico da Bahia: Solisluna, 340p, 2009.

MOTTA, G. L. O. Inventário da arborização urbana. Ação Ambiental, Viçosa, v. 2, n. 9., p.11-33, 2000.

MOURA, T. A.; SANTOS, V. L. L. V. Levantamento Quali-Quantitativo de Espécies Arbóreas e Arbustivas na Arborização Viária Urbana dos Bairros Centro e Centro Norte, Várzea Grande, Mato Grosso, Brasil. Revista da Sociedade Brasileira de Arborização Urbana, Piracicaba - SP, v.1, n.1, p.97-117, 2009.

NEVES, S. M. A. S.; NUNES, M. C. M.; NEVES, R. J. Caracterização das condições climáticas de Cáceres/MT-Brasil, no período de 1971 a 2009: subsídio às atividades agropecuárias e turísticas municipais. Boletim Goiano de Geografia. Goiânia, v. 31, n. 2, p.55-68, 2011.

NOGUEIRA, E. M. de S.; SANTOS, V. C. O. M.; CUNHA, J. S.; ANDRADE, M. J. G. Poda e Arborização Urbana. Paulo Afonso: SABEH, 76 p., 2016.

NUNES, R. L.; MARMONTEL, C. V. F.; RODRIGUES, J. P.; MELO, A. G. C. Levantamento quali-quantitativo da arborização urbana do bairro Ferraropólis na cidade de Garça - SP. Revista da Sociedade Brasileira de Arborização Urbana, Piracicaba, v.8, n.1, p. 65- 74, 2013.

PATRICIO, P. P. M. Florística e diagnóstico da arborização da Universidade Federal de Mato Grosso, campus Cuiabá. 2017. 91 f. Dissertação (Mestrado em Ciências Florestais e Ambientais), Faculdade de Engenharia Florestal da Universidade Federal de Mato Grosso, Cuiabá, 2017.

PEREIRA, G. A.; MONTEIRO, C. S.; CAMPELO, M. A.; MEDEIROS, C. O uso de espécies vegetais, como instrumento de biodiversidade da avifauna silvestre, na arborização pública: o caso do Recife. Atualidades Ornitológicas, v.125, 2005. 
PERIOTTO, F.; PITUCO, M. M.; HELMANN, A. C.; DOS SANTOS, T. O.; BORTOLOTTI, S. L. Análise da arborização urbana no município de Medianeira, Paraná. Revista da Sociedade Brasileira de Arborização Urbana, Piracicaba, v.11, n.2, p. 59-74, 2016.

PIVETTA, K. F. L.; SILVA FILHO, D. F. Arborização Urbana. Boletim Acadêmico Série Arborização Urbana UNESP/FCAV/FUNEP. Jaboticabal-SP, 2002.

PINHO, R. T. Entre monumentos e documentos: Reflexões sobre os tombamentos de Cáceres- MT. Anais XXVII Simpósio nacional de história. Natal-RN, 2013.

REDIN, C. G.; VOGEL C.; TROJAHN C. D. P.; GRACIOLI, C. R.; LONGHI, S. J. Análise da arborização urbana em cinco praças do município de Cachoeira do Sul, RS. Revista da Sociedade Brasileira de Arborização Urbana, v.5, n.3, p. 149-164, 2010.

RICHTER, B. D.; DAVIS, M. M.; APSE, C.; KONRAD, C. Short communication a presumptive standard for environmental flow protection. River Res. Applic. v. 28, p. 1312-1321, 2012.

SANCHOTENE, M.C.C. Frutíferas nativas úteis à fauna na arborização urbana. In: ENCONTRO NACIONAL SOBRE ARBORIZAÇÃO URBANA, 1., Porto Alegre, 1985. Anais... Porto Alegre, Prefeitura Municipal de Porto Alegre/ Secretaria Municipal do Meio Ambiente, p.105 - 111, 1985.

SANTOS, T. O. B.; LISBOA, C. M. C. A.; CARVALHO, F. G. Análise da Arborização Viária do Bairro de Petrópolis, Natal, RN: Uma Abordagem para Diagnóstico e Planejamento da Flora Urbana. Revista da Sociedade Brasileira de Arborização Urbana, Piracicaba - SP, v.7, n.4, p.90-106, 2012.

SEITZ, R. A. Considerações sobre a poda de árvores na arborização urbana. In: ENCONTRO NACIONAL SOBRE ARBORIZAÇÃO URBANA, 3., Curitiba, 1990. Anais... Curitiba, FUPEF, p.87-100, 1990.

SOUZA, H. S.; et al. Processo de amostragem para estimativa de produção em plantio de teca. Agrarian academy, Centro científico conhecer, v. 02, n.03, p.81-89, 2015.

STRASBURGER, E., et al. Tratado de Botânica. 7. Ed. Barcelona: Ed. Omega S.A., $1098 p, 1988$.

TEIXEIRA, I. F. Compatibilidade da Arborização de Ruas em Centros Históricos: Estudo de Caso de São Gabriel - RS. Revista R. RA'EGA - O Espaço Geográfico em Análise, Curitiba - SP, v.34, p.246-268, 2015. 